\title{
Stage-specific distribution of barnacle larvae in nearshore waters: potential for limited dispersal and high mortality rates
}

\author{
Fabián J. Tapia ${ }^{1,2, *}$, Jesús Pineda ${ }^{1}$ \\ ${ }^{1}$ Biology Department, Woods Hole Oceanographic Institution, Woods Hole, Massachusetts 02543, USA \\ ${ }^{2}$ Present address: Estación Costera de Investigaciones Marinas, Pontificia Universidad Católica de Chile, Casilla 114-D, \\ Santiago, Chile
}

\begin{abstract}
The stage-specific spatial distribution and mortality of Balanus glandula and Chthamalus spp. larvae were assessed with a series of daily vertical plankton tows collected from innershelf waters in La Jolla, Southern California, in March 2003. Sampling stations were located within $1.1 \mathrm{~km}$ of the shoreline, at depths of 10 to $45 \mathrm{~m}$. For both groups, we observed a spatial segregation of naupliar stages and cyprids, although this pattern was statistically significant for Chthamalus spp. only. Early nauplii (NII and NIII) were more abundant at the inshore stations, whereas later stages (NIV to NVI) occurred in greater numbers offshore. Cyprids were consistently more abundant at the inshore station. Such striking differences in the horizontal distributions of late nauplii and cyprids suggest limited dispersal of barnacle larvae in nearshore waters. Particle trajectories computed from current velocities measured in the area indicated that changes in vertical distribution may indeed affect dispersal, and, in some cases, enhance the retention of larvae in shallow, inner-shelf waters. Vertical life tables were used to estimate naupliar mortality rates from pooled daily stage distributions. Average estimates $( \pm \mathrm{SE})$ for the instantaneous rate of larval mortality in B. glandula $(0.33 \pm$ 0.05 larvae $\left.\mathrm{d}^{-1}\right)$ and Chthamalus spp. $\left(0.23 \pm 0.03\right.$ larvae $\left.\mathrm{d}^{-1}\right)$ were substantially higher than previously assumed for these species. We discuss the implications of limited dispersal and high mortality rates for the exchange of larvae among disjunct populations of intertidal barnacles and other coastal benthic invertebrates.
\end{abstract}

KEY WORDS: Larval distribution · Small scale · Balanus glandula Chthamalus spp. · Dispersal · Mortality Resale or republication not permitted without written consent of the publisher

\section{INTRODUCTION}

The life cycle of many coastal benthic invertebrates is characterized and shaped by differences between the environments where adults and larvae must survive and develop. Adult individuals with limited or no mobility release their larvae into the planktonic environment, where multiple physical and biological processes determine the balance between mortality, dispersal, and survival to complete development (Morgan 1995). Larvae may be transported over long distances before they reach a stage that is competent to settle onto adult habitats (Scheltema 1968), which often results in the local decoupling of recruitment and adult abundance. Coastal populations are thus considered open systems in terms of their reproductive output and local demography (Caley et al. 1996). Their persistence, structure, and dynamics are greatly influenced by mesoscale and local physical processes that mediate the dispersal of larvae to and from the shoreline (e.g. Roughgarden et al. 1988, Pineda 1991).

A number of influential studies published in the past 2 decades (e.g. Roughgarden et al. 1988, Alexander \& Roughgarden 1996, Gaylord \& Gaines 2000) used mathematical models to study the coupling of benthic population dynamics and mesoscale physical pro- 
cesses along the west coast of North America. Such models exemplify the 'supply-side' view that has dominated marine ecology in recent years (Underwood \& Fairweather 1989), wherein the renewal of coastal invertebrate populations is seen as largely dependent on the interaction of substrate availability and the occurrence of physical phenomena that transport larvae from an offshore larval pool (Roughgarden et al. 1988). Thus, local populations have been regarded as open subunits that contribute with their reproductive output to an offshore pool of larvae, and field-based research has focused on the physical processes that may transport competent larvae back to adult habitats. Timing and spatial distribution of larval settlement have been linked to the occurrence of phenomena such as linear internal waves (Norris 1963, Shanks 1983), internal tidal bores (Pineda 1991, 1994a), persistent onshore winds (Bertness et al. 1996), and the onshore displacement of surface waters during relaxation of wind-induced upwelling (e.g. Wing et al. 1995). However, comparatively little attention has been paid to the fate of pre-competent larval stages in shallow, inner-shelf waters soon or immediately after they are released by sessile adults (but see Macho et al. 2005), although recent evidence suggests that retention and self-recruitment might be more prevalent than previously thought (Warner \& Cowen 2002).

The relevance of determining how much local recruitment is given by local reproductive output, or, alternatively, finding the spatial scales at which reproduction and recruitment do correlate with each other, has been highlighted by a growing interest in marine reserves as a tool to protect habitats and biodiversity, as well as to manage marine resources under exploitation (Shanks et al. 2003). To achieve such goals, the scales of dispersal and rates of mortality experienced by larvae during their planktonic development must be known. Efforts to assess dispersal or retention have focused on the micro-chemistry of hard parts in larval fish (e.g. Swearer et al. 1999), crustaceans (DiBacco \& Levin 2000), gastropods (Zacherl et al. 2003), and bivalves (Becker et al. 2005), with varying degrees of success in terms of the spatial and temporal scales of dispersal that can be resolved (see Levin 2006 for a review). More direct approaches based on in situ tracking and intensive sampling of planktonic aggregations have been attempted for larval crustaceans (e.g. Natunewicz et al. 2001), bivalves (Arnold et al. 2005), and echinoderms (Lamare \& Barker 1999), and provided valuable information on the scales and processes that may shape the distribution of larvae relative to their parental populations.

Spatial scales of larval dispersal, which should also correspond to the scales at which disjunct populations exchange individuals (i.e. scales of connectivity), are given by the interaction of larval biology (i.e. development rates and behavior) and hydrodynamic processes in the coastal ocean. For instance, ontogenetic and inter-specific differences in vertical distribution and swimming abilities of larvae under the same advective regime may result in very distinct patterns of dispersal (e.g. Rothlisberg \& Miller 1983, Hill 1998). Dispersal may also be shaped by changes in larval mortality, with a general reduction in dispersal distances when rates of mortality increase relative to residual current velocities (Lefebvre et al. 2003, Ellien et al. 2004). However, available estimates of larval mortality in benthic invertebrates remain scarce and highly uncertain due to methodological and logistical constraints (Rumrill 1990, Morgan 1995). Mortality of larvae can be estimated directly when aggregations are tracked over time, using the observed change in larval abundance to compute a mortality rate averaged over that period. Although such tracking may be feasible in closed or semi-enclosed environments (e.g. Lamare \& Barker 1999), in open coastal waters it requires observations of plankton distribution at spatial and temporal scales that are seldom achieved (but see Natunewicz et al. 2001). Thus, laboratory (Johnson \& Brink 1998) and indirect field methods are usually employed to estimate mortality from ratios of local larval production to recruitment (e.g. Connell 1970), or from information on the stage composition of larvae over a given area (Aksnes et al. 1997).

In the present study we examined small-scale $(\sim 1 \mathrm{~km}$ from shore) patterns of horizontal distribution in larval Balanus glandula and Chthamalus spp. Our main goal was to assess the potential for early larval dispersal (i.e. shortly after hatching) through the observation of daily stage-specific distributions in shallow, inner-shelf waters. Additionally, we used daily stage structures together with a vertical life table method (Aksnes \& Ohman 1996) to estimate instantaneous mortality rates for different stage transitions. We discuss the implications of limited dispersal and high larval mortality for the exchange of propagules among disjunct populations of benthic invertebrates, as well as the limitations of our data in relation to local physical variability and larval behavior.

\section{MATERIALS AND METHODS}

Study site and species. The survey was conducted in nearshore waters off the Scripps Institution of Oceanography (SIO) pier in La Jolla, Southern California, between 6 and 13 March 2003 (hereafter Days 1 to 8 of the survey). The study area is flanked by 2 submarine canyons (Fig. 1), which are likely to influence local circulation, for example, by reflecting a substantial frac- 


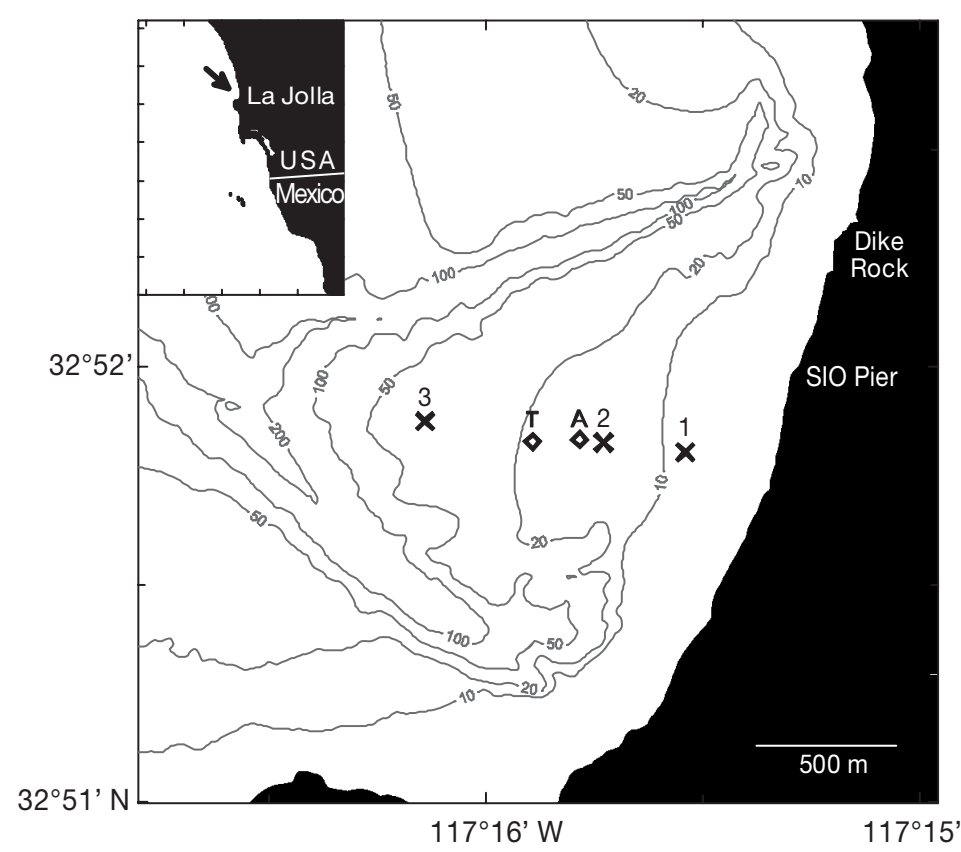

Fig. 1. Study area in La Jolla, Southern California (see inset). Numbered crosses indicate the plankton sampling stations. Diamonds labeled A and T show the location of the Acoustic Doppler Current Profiler (32 51.833' N, 117 $\left.{ }^{\circ} 15.786^{\prime} \mathrm{W}\right)$ and temperature mooring $\left(32^{\circ} 51.827^{\prime} \mathrm{N}, 117^{\circ} 15.894^{\prime} \mathrm{W}\right)$, respectively. Contour lines indicate depth in meters (bathymetric data courtesy of S. Elgar, Woods Hole Oceanographic Institution)

tion of the infra-gravity wave energy propagating onshore (Thomson et al. 2005). Additionally, local flows may be affected by a large bed of the giant kelp Macrocystis pyrifera the northern tip of which reaches up to the marine reserve adjacent to our study area.

The intertidal barnacles on which our study was focused are 2 of the most abundant species found along the United States west coast. The acorn barnacle Balanus glandula Darwin, 1854 occurs in the high to middle intertidal zone along the west coast of North America from the Aleutian Islands to Punta Baja, Baja California (Newman \& Abbott 1980, authors' pers. obs.). Chthamalus fissus is found from San Francisco to Baja California (Newman \& Abbott 1980), and dominates the high to upper middle intertidal at La Jolla. Its latitudinal distribution, however, occasionally overlaps with that of $C$. dalli, a northern species found from Alaska to a southern limit that oscillates between Point Conception (Wares 2001) and San Diego (Newman \& Abbott 1980). Although adult C. fissus and C. dalli can be identified by dissection and microscopic examination (Newman \& Abbott 1980), their larvae are morphologically identical (Miller et al. 1989). Thus, chthamalid larvae will be referred to as Chthamalus spp., as our larval identification was based solely on morphological criteria (see below).

The timing of our survey was based on the known reproductive cycle of Balanus glandula and Chthamalus fissus, and aimed at finding larvae of both species in nearshore waters. Chthamalus settlers can be found year round at a wide range of tidal heights in Central and Southern California (Hines 1979, Pineda 1994b, authors' unpubl. obs.). Individuals reach sexual maturity ca. 2 mo after settlement, after which up to 16 small broods are continuously produced each year (Hines 1979). Adult B. glandula, in contrast, produce 2 to 6 broods over a reproductive season that extends from early winter to late spring (Barnes \& Barnes 1956, Hines 1979, Newman \& Abbott 1980). Settlement takes place from late winter to early summer (Hines 1979, authors' unpubl. obs.).

Sampling procedure. Plankton samples were collected daily from 3 stations located within $0.3,0.6$, and $1.1 \mathrm{~km}$ of the shoreline, at depths of 10 to $40 \mathrm{~m}$ (Fig. 1). Plankton was collected by vertically towing a $110 \mu \mathrm{m}$ mesh net ( $0.75 \mathrm{~m}$ diameter, $2.75 \mathrm{~m}$ length) from bottom to surface. The water volume sampled at each station was estimated using a mechanical flowmeter (General Oceanics 2030). Samples were taken into the laboratory and preserved in $95 \%$ ethanol.

The classification of larvae by species and stage was based on the morphological descriptions published for Balanus glandula (Branscomb \& Vedder 1982, Brown \& Roughgarden 1985) and Chthamalus spp. (Miller et al. 1989). We only report the abundance of naupliar stages NII through NVI, as NI larvae molt into NII within hours of hatching at the temperatures recorded in our survey (Brown \& Roughgarden 1985, Miller et al. 1989).

Spatial patterns in the distribution of different larval stages were analyzed using a 2-way analysis of variance (ANOVA) without replicates, in which tows made on different days at a given station were treated as repeated observations. We tested for homogeneity of variances using Hartley's procedure (Hartley 1950), which is based on the ratio of the largest to smallest sampled variance and is also sensitive to nonnormality (Underwood 1997). To reach homogeneity of variances, concentrations of nauplii and cyprids were transformed as $\log (x+1)$ and $-1 /(x+1)$, respectively.

Concurrently with the plankton survey, we monitored settlement of Balanus glandula and Chthamalus spp. larvae on collectors deployed within the vertical range of the adult distribution at a nearby intertidal site (Dike Rock, Fig. 1). Collectors were made out of $11 \mathrm{~cm}$ long pieces of white PVC pipe $(2.54 \mathrm{~cm}$ diameter), which were cut in half lengthwise and etched with 3 lengthwise grooves. A hole was drilled in the center, so that the collectors could be attached to the 
substrate using stainless steel screws that were cemented into holes drilled in the rock. Settlement collectors were first deployed on Day 1 and recovered/ replaced daily during the daytime low tide until Day 8 . Tidal height and wave action precluded the recovery of collectors on Day 4. Barnacles on recovered collectors were identified and enumerated using a dissecting microscope. Only larvae that settled within ca. $0.16 \mathrm{~mm}$ of the intersection between the groove bottom and wall were counted, since settlement rarely occurs outside this area. Hence, the area of substrate per collector was $\sim 1.9 \mathrm{~cm}^{2}$ (Pineda 1994b). Settlement rates were calculated as the number of settlers per plate per day of deployment.

Environmental variables. From Day 1, temperature in the water column was recorded at 1 min intervals with Onset Stowaway XTI loggers (response time $<15 \mathrm{~s})$, located at the water surface and at $1,2,4,6,8$, 10, 12, and 14 meters above the bottom (mab). The string of loggers was deployed at a depth of ca. $18 \mathrm{~m}$ (Fig. 1). Current velocities were measured with a bottom-mounted 1200 kHz Acoustic Doppler Current Profiler (ADCP, RD Instruments), deployed on Day 1 near Stn 2 at a depth of ca. $16 \mathrm{~m}$ (Fig. 1). Measurements were recorded in $1 \mathrm{~m}$ bins at 1 min intervals (60 pings per ensemble). Due to the temporal variability in water depth introduced by tidal fluctuations, surface wave action, and side lobbing, data collected from the surface bins had to be discarded. The uppermost bin with reliable data was at $13 \mathrm{mab}$, which was on average $3 \mathrm{~m}$ below the surface. ADCP data were rotated and aligned with the main axis of variability for horizontal currents $\left(14^{\circ}\right.$ with respect to true north), which roughly paralleled the shoreline orientation. The orientation of this axis was given by the major eigenvector of a covariance matrix computed for depth-averaged east and north velocities. The same axis was used to rotate hourly wind observations, which were obtained from the SIO Coastal Data Information Program website (http://cdip.ucsd.edu). ADCP and wind data were partitioned into along-shore and cross-shore components.

Assessment of potential dispersal-progressive vector diagrams. We explored the effect that nearshore horizontal flows could have on the distribution of barnacle larvae by means of progressive vector diagrams (PVD). Constructing such diagrams hinges on the assumption that horizontal currents measured at a single point are representative of a larger area. This is clearly a strong assumption given the small-scale heterogeneity that local bathymetry (Fig. 1) may induce on inner-shelf circulation. Keeping these limitations in mind, we used PVD as a first-order approach to project the expected residence of drifting particles in nearshore waters at the study area. Our goal was to assess for how long a passively drifting or actively swimming larva was likely to remain within a small area in nearshore waters. Near-surface velocities measured by bottom-mounted current meters might fail to predict the trajectory of particles found in the uppermost layer of the water column (Tapia et al. 2004). However, we assumed that the section of the water column for which reliable current meter data were available (1.5 to $13.5 \mathrm{mab}$, i.e. an average of $3 \mathrm{~m}$ below the surface) is representative of the vertical range of larval distribution.

The PVD were computed as predicted $(x, y)$ positions at time $t_{n}$ :

$$
x\left(t_{n}\right)=\Delta t \sum_{i=1}^{n} u\left(t_{i}\right), \quad y\left(t_{n}\right)=\Delta t \sum_{i=1}^{n} v\left(t_{i}\right)
$$

where $u\left(t_{i}\right)$ and $v\left(t_{i}\right)$ are the east and north current speeds measured by the current meter at a given depth at Time $t_{i}$ and $\Delta t$ is the sampling interval (Emery \& Thomson 1998, p. 165). We computed PVD for particles with 4 different types of vertical distribution. First, particles were assumed to be uniformly distributed in the water column; hence, depth-averaged current velocities were used to calculate trajectories from Eq. (1). For the second and third patterns of vertical distribution, it was assumed that larvae remain in the bottom half (i.e. near-bottom) and upper half (i.e. near-surface) of the water column at all times, and trajectories were computed using current velocities averaged over the corresponding depth range. Finally, particles were assumed to perform diel vertical migrations (DVM), so that they occurred near the bottom during the day (here defined as 06:00 to 18:00 h PST) and near the surface at night.

Trajectories for all 4 vertical distributions were computed repeatedly for drifting periods that ranged from 0.5 to $5 \mathrm{~d}$. For each type of vertical distribution and drifting period, 100 starting times were chosen at random from the available dataset. Results are reported as the mean fraction of trajectories whose endpoints fell inside an elliptical area with a major axis of length $a=5 \mathrm{~km}$ and a minor axis $b=0.28 a$. While the length of this ellipse was arbitrarily chosen, its shape was given by the depth-averaged ratio between the minor and major axes of variability for observed current velocities. As rotated currents were used to compute particle trajectories, the ellipse was rotated accordingly, with its major axis at $14^{\circ}$ with respect to true north.

Estimation of larval mortality. Vertical life tables (Aksnes \& Ohman 1996) were used to estimate the mortality of nauplius larvae. The method yields estimates of mortality at the transitions between contiguous larval stages, and is recommended for cases where advection is expected to affect the horizontal distribution of larvae (Aksnes et al. 1997). Mortality is estimated from instantaneous stage distributions (i.e. obtained at 1 point in time); hence, it is not necessary 
to track a particular larval aggregation. Instead, the stage distribution must be representative of the population under study, and spatial coverage and resolution should be large enough to compensate for the effect of small-scale patchiness.

Below we summarize the derivations of a method presented by Aksnes \& Ohman (1996, p. 1462). Three main assumptions are made: (1) daily recruitment $\left(\rho_{i}\right)$ to a given Stage $i$ is constant over the duration of that stage, (2) the duration of a stage $\left(\alpha_{i}\right)$ is constant and equal for all individuals in the same stage, and (3) the mortality over that period $\left(\theta_{i}\right)$ is constant. Thus, the number of nauplii in Stage $i$ on Day $x$ can be expressed as:

$$
n_{i}=\rho_{i} \int_{x-\alpha_{i}}^{x} \exp \left[-\theta_{i}(x-t)\right] \mathrm{d} t=\frac{\rho_{i}}{\theta_{i}}\left[1-\exp \left(-\theta_{i} \alpha_{i}\right)\right]
$$

which is equal to the number of larvae that recruited during the last $\alpha_{i}$ days and survived (Aksnes \& Ohman 1996). If it is also assumed that the mortality rate is constant for a period equal to the duration of 2 consecutive stages $i$ and $i+1$, then the number of nauplius larvae in Stage $i+1$ on Day $x$ is:

$n_{i+1}=\rho_{i+1} \int_{x-\alpha_{i+1}}^{x} \exp [-\theta(x-t)] \mathrm{d} t=\frac{\rho_{i+1}}{\theta}\left[1-\exp \left(-\theta \alpha_{i+1}\right)\right]$

The number of cyprid larvae, for which the stage duration $\alpha_{c}$ is assumed infinite by the analysis, can be expressed as:

$$
n_{c}=\rho_{c} \int_{-\infty}^{x} \exp \left[-\theta_{c}(x-t)\right] \mathrm{d} t=\frac{\rho_{c}}{\theta_{c}}
$$

Finally, the rate of recruitment to Stage $i+1$ is the product of recruitment to the previous Stage $i$ and the stage-specific survival:

$$
\rho_{i+1}=\rho_{i} \exp \left(-\theta_{i} \alpha_{i}\right)
$$

An equation that relates the relative abundance of 2 consecutive stages with their duration and mortality rate can be obtained by combining Eqs. (2), (3), and (5), and by setting $\theta_{i}=\theta$ :

$$
\frac{n_{i}}{n_{i+1}}=\frac{\exp \left(\theta \alpha_{i}\right)-1}{1-\exp \left(-\theta \alpha_{i+1}\right)}
$$

Similarly, an equation that relates the number of NVI and cyprid larvae can be obtained by combining Eqs. (2), (4), and (5).

$$
\theta=\frac{1}{\alpha_{V I}} \ln \left(\frac{n_{V I}}{n_{C}}+1\right)
$$

Eq. (6) was solved iteratively to obtain estimates of the mortality rate at the transition between naupliar stages NII to NV. The estimated mortality of NVI larvae was obtained directly from Eq. (7). Estimates of the number of individuals per stage for each day with plankton observations (Days 1 to 7 ) were obtained by pooling larval counts recorded at the 3 stations. An average stage duration of $3 \mathrm{~d}$ was used for Chthamalus spp. (Miller et al. 1989), whereas durations of 1, 2, 2, 3, and $3 \mathrm{~d}$ were used for Balanus glandula NII, NIII, NIV, NV, and NVI (Brown \& Roughgarden 1985).

\section{RESULTS}

\section{Spatial-temporal distribution of larval stages}

Patterns of spatial distribution for different larval stages were consistent among species. In general, earlier naupliar stages (NII and NIII) were more abundant at the inshore stations, whereas later stages (NV and NVI) increased in abundance towards the offshore station (Fig. 2). The statistical analysis of stage-specific distributions indicated no significant among-station differences for any but one larval stage in Balanus glandula (NII, Table 1). Conversely, the analysis of Chthamalus spp. distributions indicated significant spatial differences in all but one case (NII, Table 1). The concentration of $B$. glandula NII larvae at the offshore station was significantly lower than at the inshore stations (Table 1). On the other hand, concentrations of Chthamalus spp. NIV, NV, and NVI larvae were significantly higher at the offshore station. Although not statistically significant for B. glandula, concentrations of cyprids were higher at the inshore stations (Fig. 2F,L) and resembled the distribution of NII (Fig. 2A,G) rather than the preceding naupliar

Table 1. Balanus glandula and Chthamalus spp. Results of 2way ANOVAs used to test for spatial (between-station) differences in the concentration of each larval stage. Different days of the study were treated as repeat observations $(\mathrm{df}=2,6$ for

\begin{tabular}{|c|c|c|c|}
\hline Species/stage & $F_{2,6}$ & $\mathrm{p}$ & Pairwise differences \\
\hline \multicolumn{4}{|c|}{ Balanus glandula } \\
\hline NII & 10.973 & 0.002 & $\operatorname{Stn} 1>\operatorname{Stn} 3, \operatorname{Stn} 2>\operatorname{Stn} 3$ \\
\hline NIII & 3.168 & 0.082 & \\
\hline NIV & 1.254 & 0.323 & \\
\hline NV & 1.872 & 0.200 & \\
\hline NVI & 3.533 & 0.065 & \\
\hline Cyprids & 2.451 & 0.132 & \\
\hline \multicolumn{4}{|c|}{ Chthamalus spp. } \\
\hline NII & 3.120 & 0.089 & \\
\hline NIII & 6.508 & 0.015 & $\operatorname{Stn} 2>\operatorname{Stn} 1$ \\
\hline NIV & 25.373 & 0.000 & $\operatorname{Stn} 3>\operatorname{Stn} 1, \operatorname{Stn} 2>\operatorname{Stn} 1$ \\
\hline NV & 32.301 & 0.000 & $\operatorname{Stn} 3>\operatorname{Stn} 1, \operatorname{Stn} 2>\operatorname{Stn} 1$ \\
\hline NVI & 28.256 & 0.000 & $\operatorname{Stn} 3>\operatorname{Stn} 1, \operatorname{Stn} 2>\operatorname{Stn} 1$ \\
\hline Cyprids & 10.326 & 0.004 & $\operatorname{Stn} 1>\operatorname{Stn} 3$ \\
\hline
\end{tabular}
all tests). Significant between-station differences are indicated in bold. The results of Tukey pairwise comparisons, performed for each test with a significant between-station effect, are shown in the third column for each species 


\section{Balanus glandula}
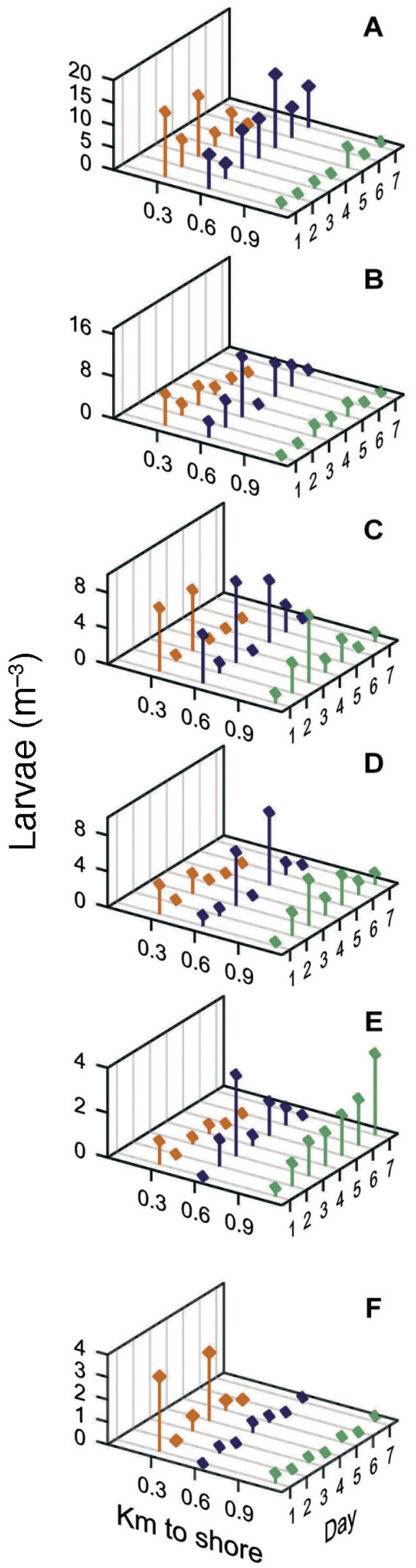

Chthamalus spp.

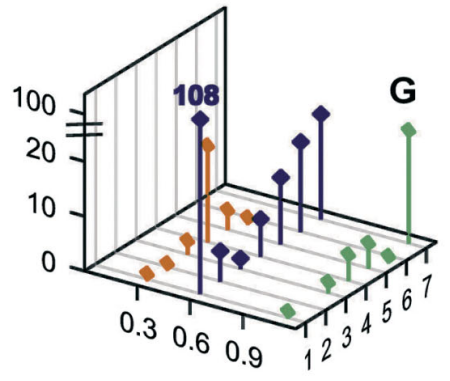

NII

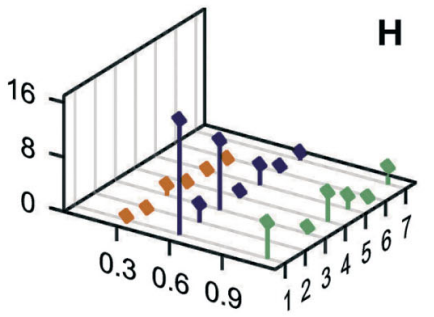

NIII
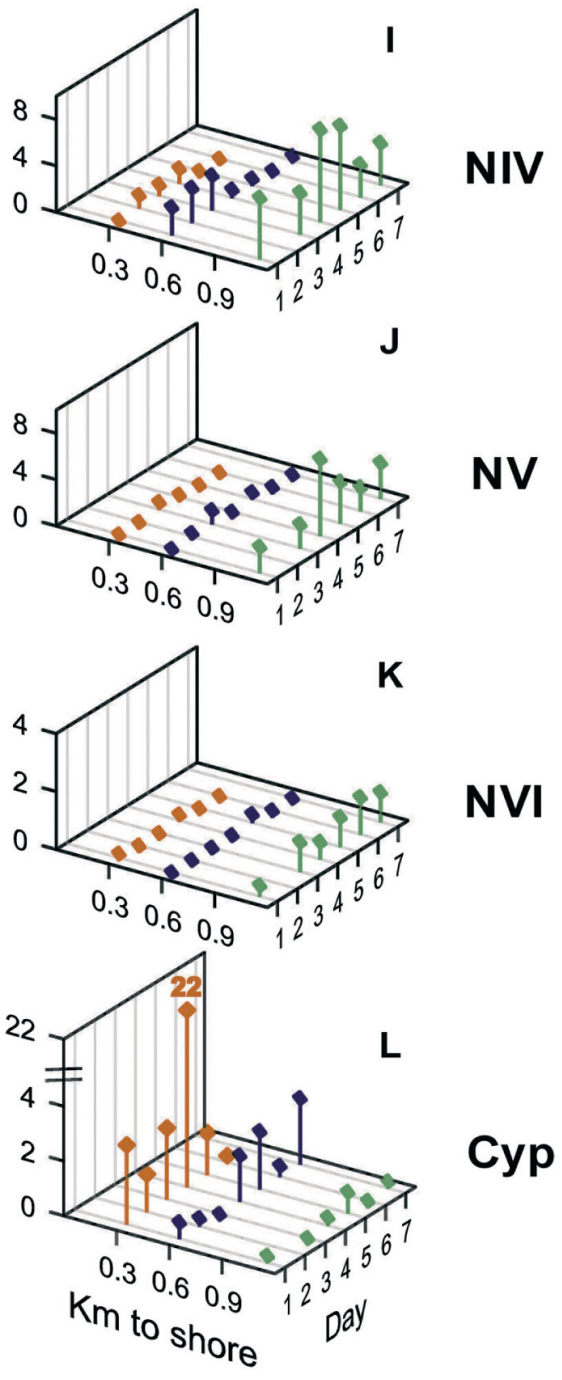

Fig. 2. (A-F) Balanus glandula and (G-L) Chthamalus spp. Temporal variability in the stage-specific spatial distribution of naupliar (NII to NVI) and cyprid (Cyp) larvae in shallow, inner-shelf waters off La Jolla, Southern California 
stage (i.e. NVI). Patchiness in larval distribution appeared to be species specific. For example, on Day 1, the concentration of $B$. glandula NII decreased steadily from 14.5 to 1.5 ind. $\mathrm{m}^{-3}$ between the inshore and offshore stations (Fig. 2A), whereas Chthamalus spp. NII peaked at Stn 2, with 108 ind. $\mathrm{m}^{-3}$, i.e. 2 orders of magnitude higher than concentrations observed at the other 2 stations (Fig. 2G).

\section{Temporal variability in stage distribution}

Daily stage distributions for Balanus glandula and Chthamalus spp. (Fig. 3A-G and $\mathrm{H}-\mathrm{N}$, respectively) were obtained by pooling larval counts from the 3 sampling stations. All stages of larval development in $B$. glandula were observed on all but one day of the survey (Fig. 3F). Stage distributions of B. glandula were dominated by NII and NIV during the first $3 \mathrm{~d}$ of the survey (Fig. 3A-C). NII larvae were numerically dominant on subsequent days (Fig. 3D-G), suggesting a constant input of newly hatched larvae either released by local adults or advected into the study area from adjacent populations. Stage distributions of Chthamalus spp. larvae were dominated by NII on 5 out of $7 \mathrm{~d}$ of observations (Fig. $3 \mathrm{H}-\mathrm{N}$ ), but most notably on Days 5 to 7 (Fig. 3L-N). This suggests a continuous input of larvae released locally or at a site from which these larvae can be advected within the time it takes for the NII to NIII transition to occur ( $3 d_{\text {; }}$ Miller et al. 1989). Finally, on Days 3 to 5 we observed a high abundance of Chthamalus spp. cyprids relative to the abundance of NVI larvae (Fig. 3J-L), which suggests that cyprids are either accumulated over time or transported into the study area from an external source (see 'Discussion').

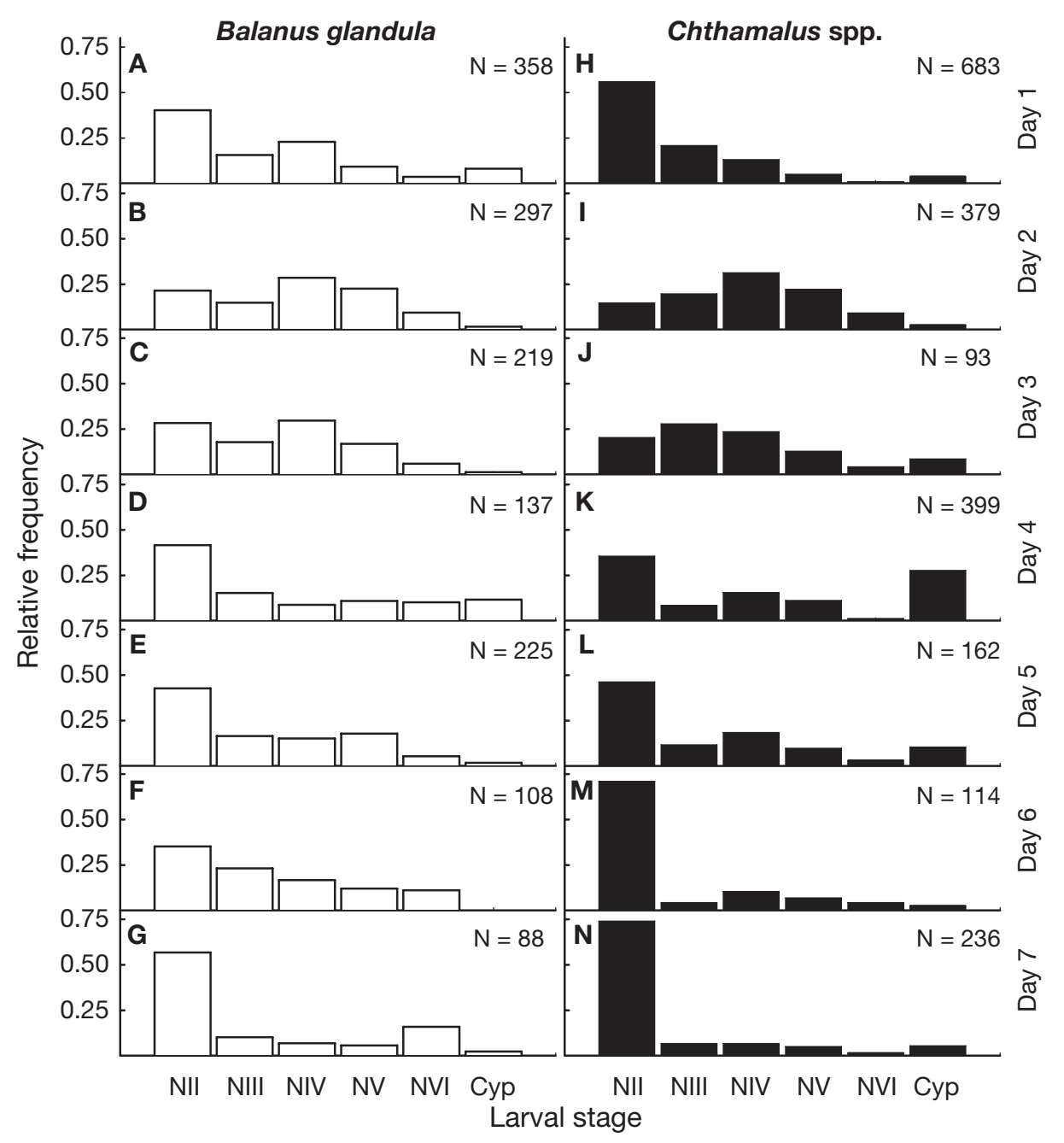

Fig. 3. (A-G) Balanus glandula and $(\mathrm{H}-\mathrm{N})$ Chthamalus spp. Stage distributions of larvae for each day of the survey $($ Day $1=$ 6 March 2003). Relative stage frequencies were computed from total counts of larvae (N) at the 3 sampling stations 

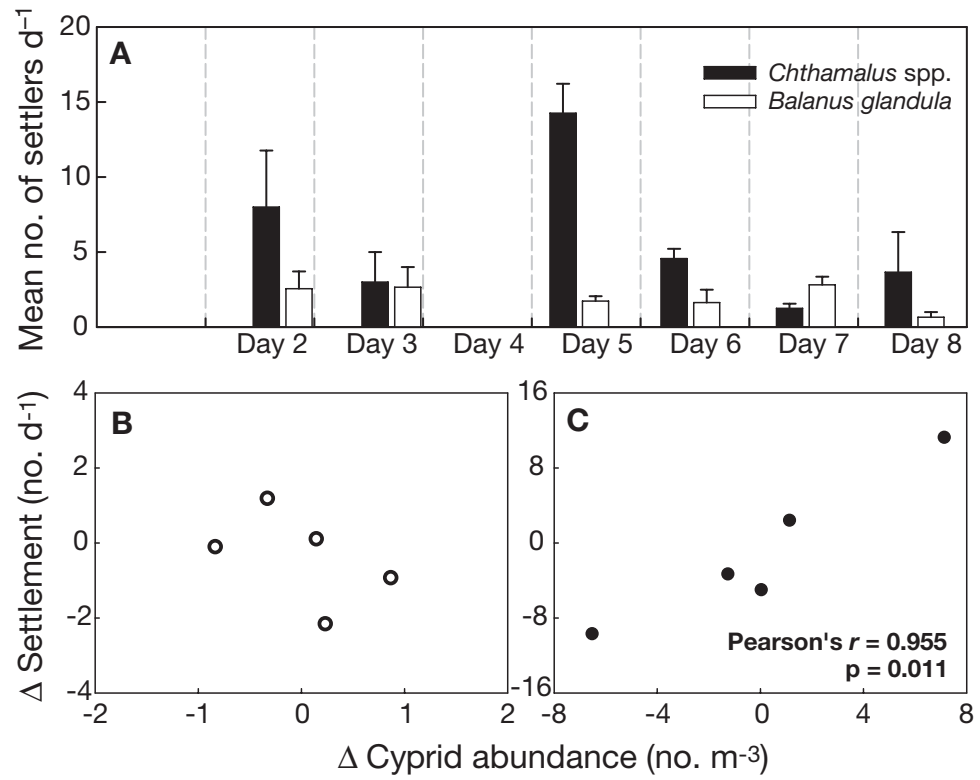

Fig. 4. Balanus glandula and Chthamalus spp. (A) Larval settlement at Dike Rock, and the correlation between daily changes in settlement and daily changes in nearshore cyprid concentration for (B) B. glandula and (C) Chthamalus spp.

\section{Settlement and environmental variables}

Settlement of both species was observed at Dike Rock throughout the survey (Fig. 4). In general, and consistent with their higher abundance in the plankton (Fig. 2L), settlement rates of Chthamalus spp. cyprids were higher than those observed for Balanus glandula (Fig. 4A). Settlement of Chthamalus spp. cyprids peaked on Day 5 of our study (Fig. 4A), 1 d after their maximum nearshore abundance was observed (Fig. 2L). Finally, while the timing of settlement in B. glandula was not correlated with changes in cyprid abundance at the inshore station (Fig. 4B), daily changes in the rate of settlement of Chthamalus spp. larvae were positively correlated with daily changes in their concentration at the inshore station (Fig. 4C).

With the exception of Day 4, all of our plankton collections were conducted during periods of relative calm that coincided with the transition from nighttime to daytime winds (Fig. 5A). On several days (1 and 2, 6 to 8), the diurnal pattern of wind variability resembled that shown by the summertime daily sea breeze, with afternoon winds blowing onshore at velocities of up to $3.5 \mathrm{~m} \mathrm{~s}^{-1}$ (Fig. 5A). Nighttime winds showed greater variability, and occasionally blew offshore with intensities similar to those recorded during the day. There was a change in the regime of wind variability on Days 4 and 5, with afternoon and evening winds blowing persistently towards the southeast (Fig. 5A). Local hydrodynamics during the survey were dominated by along-shore barotropic flows (Fig. 5B), which were more energetic (up to $17 \mathrm{~cm} \mathrm{~s}^{-1}$ ) than cross-shore currents (up to $10 \mathrm{~cm} \mathrm{~s}^{-1}$; Fig. 5C) and explained an average of $80 \%$ of the total variability between 2 and 13 mab (i.e. range of usable bins). Periodicity in the along-shore flow was dominated by the barotropic tide, with semi-diurnal changes in current direction throughout the water column (Fig. 5B). The vertical structure of cross-shore flows, on the other hand, was consistent with the structure of Mode 1 internal motions, often showing 2 layers of variable thickness and opposite flow directions (Fig. 5C). Temperature measurements showed a stratified water column, with differences between the surface and the bottom that reached ca. $5^{\circ} \mathrm{C}$ on Day 7 (Fig. 5D). Semidiurnal fluctuations in temperature distribution, associated with the tidal cycle were observed throughout the survey. An internal tidal bore warm front was detected in the afternoon of Day 3 (Fig. 5D). The occurrence of this bore coincided with an increase in the velocity of onshore currents throughout the water column, especially near the bottom (Fig. 5C), as well as a change in the vertical structure of along-shore velocities (Fig. 5B). Unfortunately, a high tide made it impossible to record settlement on Day 4, following the occurrence of such feature; maximum Chthamalus spp. settlement was nevertheless recorded on Day 5 (Fig. 4A).

\section{Progressive vector diagrams}

Trajectories obtained from our PVD calculations confirmed the notion that vertical distribution of larvae may greatly affect their dispersal in nearshore waters (Fig. 6). When PVD were calculated with horizontal velocities measured at the study site, nearly $20 \%$ of near-surface and uniformly distributed particles were retained for up to $2 \mathrm{~d}$ within a $5 \mathrm{~km}$ ellipse, whereas all near-bottom and vertically migrating particles had left the same area by then (Fig. 6). Results of the same calculations for data gathered at another station (ca. $5 \mathrm{~km}$ NW) in 2004 also revealed that vertical position influenced drifting times (results not shown).

\section{Mortality estimates}

The high variability observed in daily stage distributions (Fig. 3) precluded estimation of mortality for all stage transitions. A number of estimates that were $>1$ or $<0$ were obtained when such an approach was used 
(results not shown), most likely as a result of differential advection of larval stages and the consequent violation of a basic assumption of the vertical life table method. We pooled larval counts for the contiguous stages NII/NIII and NIV/NV and obtained mortality estimates for the transitions NII + NIII $\rightarrow$ NIV + NV, NIV + NV $\rightarrow$ NVI, and NVI $\rightarrow \mathrm{C}$ (Table 2). Average mortality rates estimated by stage transition ranged between 0.298 and 0.396 larvae $\mathrm{d}^{-1}$ for Balanus glandula and between 0.176 and 0.309 larvae $\mathrm{d}^{-1}$ for Chthamalus spp. There was no apparent tendency in the average values, or in the variability of mortality estimates, to decrease towards later stage transitions (Fig. 7). Average mortality rates $( \pm \mathrm{SD})$ computed across stage transitions and days were $0.329( \pm 0.197)$ larvae $\mathrm{d}^{-1}$ for B. glandula and 0.232 $( \pm 0.143)$ larvae $\mathrm{d}^{-1}$ for Chthamalus spp.
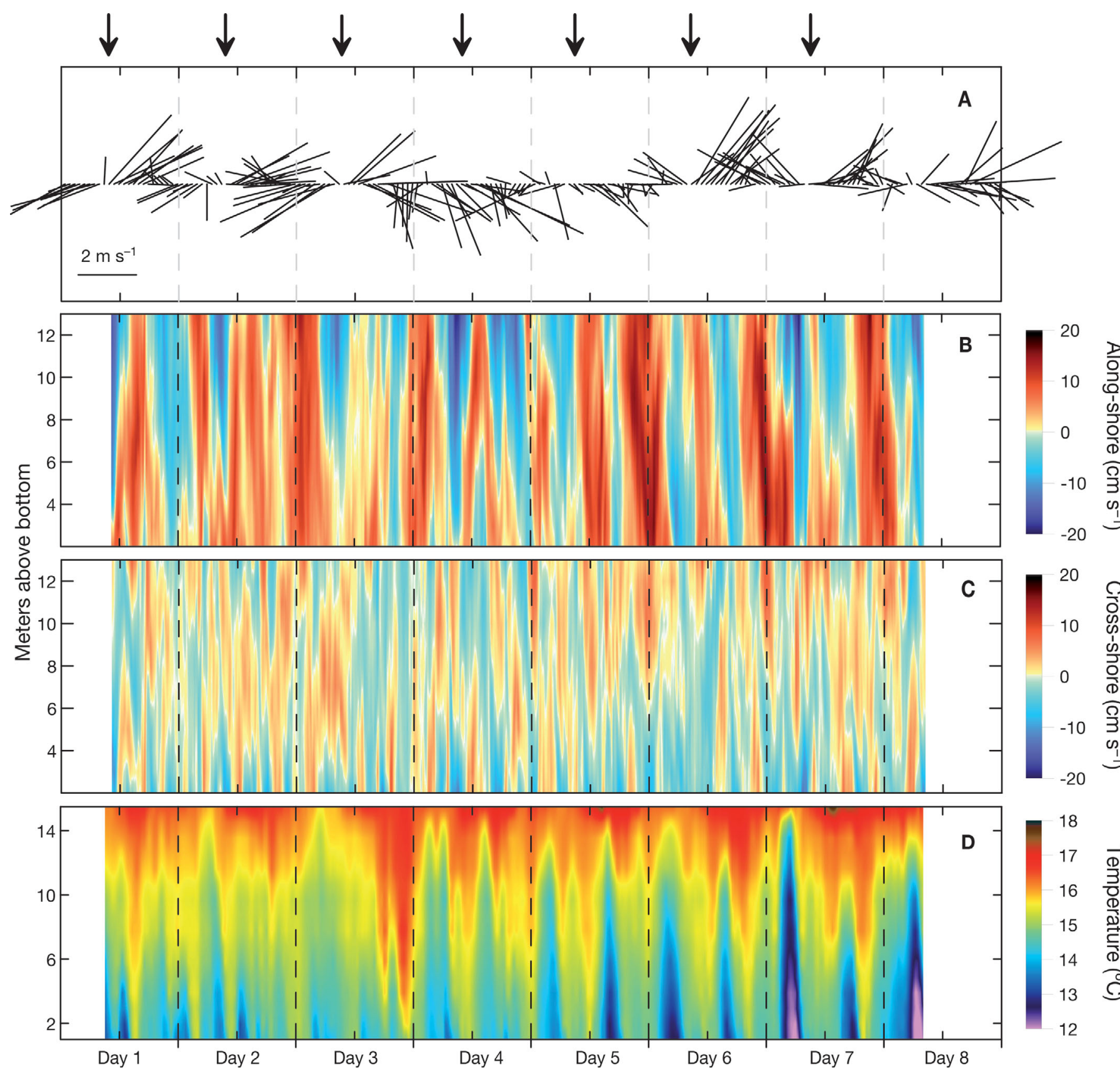

Fig. 5. Time series of environmental variables measured at the study area. Arrows indicate the times at which plankton collections were conducted. (A) Hourly observations of wind velocity were gathered at the Scripps Institution of Oceanography pier. The series of (B) along-shore and (C) cross-shore horizontal currents (both in $\mathrm{cm} \mathrm{s}^{-1}$ ) and (D) temperature distribution were plotted using low-pass-filtered series of 10-point (i.e. $10 \mathrm{~min}$ ) running means 


\section{DISCUSSION}

Prior to this study, we expected all larval stages to be well mixed (i.e. exhibit similar horizontal distributions) within the small area encompassed by our nearshore plankton survey. Instead, we have found persistent stage-specific patterns of larval distribution that suggest a potential for limited dispersal in nearshore waters. At the same time, we obtained estimates of larval mortality rates that are substantially higher than previously assumed (see Gaylord \& Gaines 2000, p. 774). However, large daily fluctuations in the stage structure of Balanus glandula and Chthamalus spp. larvae indicated that the spatial coverage and resolution of our sampling were insufficient to compensate for nearshore advection and small-scale patchiness; hence, a central assumption of the mortality estimation method was probably not met. Despite the apparent effect of advection on the pooled stage structures, the consistent finding of late naupliar stages within ca. $1 \mathrm{~km}$ from shore suggests that a fraction of these intertidal barnacle larvae may complete their development in shallow, inner-shelf waters. The generality of our observations, however, must be tested at sites with different coastal configurations and bathymetries, as 2 submarine canyons flanking the area (Fig. 1) may affect local circulation in a way that promotes larval retention. Indeed, horizontal flows and their alongshore and crossshore variability at scales of 0.1 to $10 \mathrm{~km}$, together with stage-specific patterns of vertical distribution, must be better described in order to assess the chances of dispersal versus retention faced by benthic invertebrate larvae in nearshore environments.

Table 2. Balanus glandula and Chthamalus spp. Estimates of mortality (ind. $\mathrm{d}^{-1}$ ) obtained for each day and stage transition. Empty cells correspond to days/transitions for which the estimated mortality rate was zero or negative

\begin{tabular}{|lccc|}
\hline \multirow{2}{*}{$\begin{array}{l}\text { Species/ } \\
\text { day }\end{array}$} & \multicolumn{4}{c|}{$\begin{array}{l}\text { Mortality estimates per stage } \\
\text { NII + NIII } \rightarrow\end{array}$} & $\begin{array}{c}\text { NIV + NV } \rightarrow \\
\text { NIV + NV }\end{array}$ & NVI $\rightarrow$ \\
& & & NVI \\
\hline Balanus glandula & & & \\
1 & 0.279 & 0.393 & 0.123 \\
2 & 0.043 & 0.282 & 0.629 \\
3 & 0.128 & 0.366 & 0.558 \\
4 & 0.421 & 0.036 & 0.210 \\
5 & 0.288 & 0.311 & 0.462 \\
6 & 0.322 & 0.108 & - \\
7 & 0.603 & - & 0.693 \\
Chthamalus spp. & & & \\
1 & 0.239 & 0.441 & 0.082 \\
2 & - & 0.224 & 0.501 \\
3 & - & 0.300 & 0.135 \\
4 & 0.083 & 0.475 & 0.015 \\
5 & 0.119 & 0.315 & 0.086 \\
6 & 0.243 & 0.149 & 0.327 \\
7 & 0.320 & 0.262 & 0.089 \\
\hline
\end{tabular}

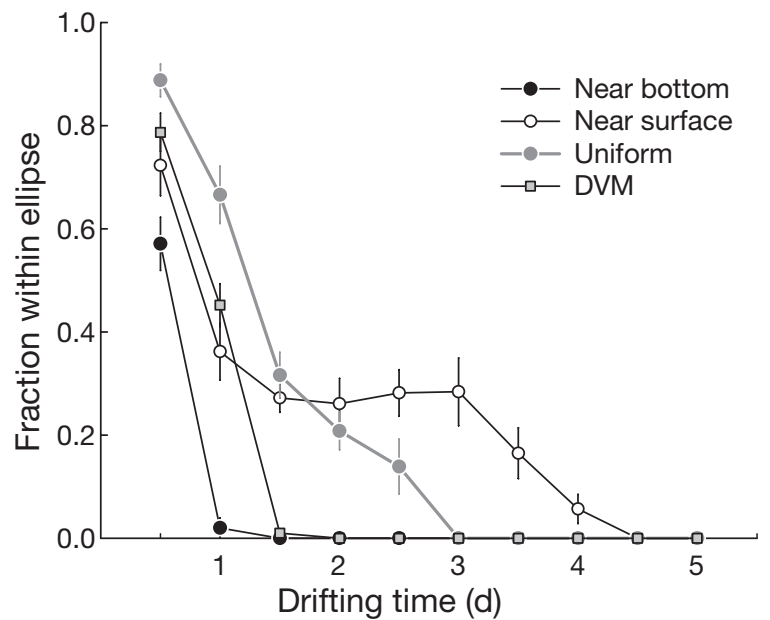

Fig. 6. Expected residence in the nearshore for drifting particles with different patterns of vertical distribution: near bottom, near surface, uniform, and diel vertical migration (DVM). Values correspond to the mean fraction of 100 simulated trajectories that remained within an elliptical area defined by a major axis of length $a=5 \mathrm{~km}$ and minor axis of $b=$ $0.28 a=1.4 \mathrm{~km}$. Trajectories were calculated from horizontal current velocities measured at the study area in March 2003. Error bars $=\mathrm{SD}$

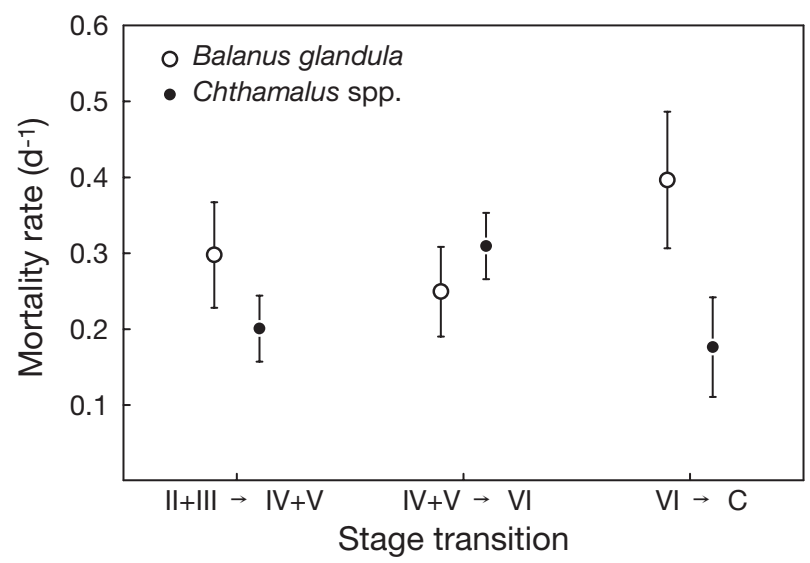

Fig. 7. Average estimates of the instantaneous rate of larval mortality $( \pm$ SE) for 3 stage transitions in Balanus glandula and Chthamalus spp.

\section{Spatial distribution of larvae}

The daily changes we observed in larval stage distributions suggest that there was a continuous input of early nauplii (NII) into nearshore waters, especially after Day 4. A change in the pattern of local wind forcing observed on Days 4 and 5, blowing persistently towards the southeast, may have had a role on the change observed in nearshore stage distributions and settlement rates of Chthamalus spp. larvae. Additionally, the persistent spatial pattern observed for early nauplii, with higher concentrations of NII at Stns 1 and 
2, suggests that larvae produced by local adults were hatching at the time of our study. Recently hatched barnacle larvae have a positive phototactic response (Lang et al. 1979) and sustained onshore wind forcing may promote the nearshore retention of surface waters and suspended material (McQuaid \& Phillips 2000, Tapia et al. 2004). Local topography and shoreline orientation may have further promoted the retention of early stages in shallow, inner-shelf waters at the study area. As for later stages, unpublished observations conducted every $2 \mathrm{~h}$ and over a $48 \mathrm{~h}$ cycle near the study area in May 2003 (F. Tapia, J. Pineda, C. DiBacco \& J. Jarett unpubl. data) indicate that ca. $90 \%$ of all barnacle nauplii are found near the surface at any given time. Thus, it seems feasible for a larva to be retained throughout its planktonic development at areas where local hydrodynamics and external physical forcing promote the nearshore retention and/or accumulation of surface waters. The Southern California Bight, where upwelling-favorable atmospheric forcing tends to be weak (Winant 1983), or smaller areas located in what has been termed 'upwelling shadows' (Graham \& Largier 1997), are expected to provide such conditions and hence to exhibit higher rates of larval arrival to adult habitat. Recent observations conducted during 5 consecutive seasons indicate that Chthamalus spp. settlement rates at La Jolla are over 100 times greater than at a site located $100 \mathrm{~km}$ to the south (Pineda \& López 2002). At smaller spatial scales, comparisons of invertebrate settlement rates among 16 sites that span $120 \mathrm{~km}$ of active-upwelling shoreline in the southeastern Pacific (Lagos et al. 2005) have shown consistently higher settlement at a site that appears to be located in an upwelling shadow (Narvaez et al. 2004). Observations of stage-specific nearshore larval distributions were not gathered during these studies.

Larvae of both Balanus glandula and Chthamalus spp. settled at Dike Rock throughout the survey, indicating that cyprids found in our inshore plankton samples were competent to settle. Cyprid concentrations at the inshore station were higher than those of NVI larvae, suggesting that cyprids did not settle immediately after molting from a NVI larva and were accumulated over an undetermined number of days, or that they were advected into our study area from an external source of late-stage nauplii, including those located further offshore than our external station $(1.1 \mathrm{~km})$. Despite such limitation in spatial coverage, our observations suggest that cross-shelf distributions of cyprids and NVI larvae are dictated by different sets of physical and behavioral factors. Nauplii and cyprids are likely to exhibit different behaviors, especially in terms of their swimming capabilities, and cyprids might be able to respond to transient hydrodynamic features that could transport them onshore (Helfrich \& Pineda
2003). Our measurements of current velocities and previous descriptions of physical scales of variability in the region (Winant \& Bratkovich 1981) indicate that nearshore larval distributions should be greatly influenced by alongshore flows, which were barotropic and explained an average of $80 \%$ of the total variability in nearshore horizontal velocities. This implies that all larval stages are likely to experience passive dispersal on the alongshore axis, and that higher concentrations of cyprids at the inshore station must have resulted from the interaction of stage-specific behavior, duration of the cyprid stage, and the dynamics of crossshore flows. The vertical distribution of cyprids and their responses to transient hydrodynamic features must be determined in order to further investigate this question.

\section{Assessing larval dispersal in nearshore waters}

As larvae develop in the plankton, they acquire behaviors that could either increase dispersal or facilitate retention near their natal sites (e.g. Bousfield 1955). Mortality and dilution, on the other hand, cause a decrease in the abundance of larvae in nearshore waters to an extent that is currently unknown for most species (but see Ellien et al. 2004). Because tagging larvae to estimate mortality and dispersal through a mark-recapture approach has numerous disadvantages and logistical limitations (see Levin 1990), especially for larvae that are as small and abundant as the larvae of intertidal barnacles, natural tags such as environmentally induced chemical signatures have become a promising tool to assess dispersal of fish and invertebrate larvae over scales of days to months (e.g. Swearer et al. 1999). However, the applicability of this approach to tracking crustacean larvae is very limited, given the loss of hard structures during ecdysis. For instance, NI larvae of Balanus glandula and Chthamalus spp. molt into NII within hours of hatching (Brown \& Roughgarden 1985, Miller et al. 1989). Therefore, in order to assess the dispersal of crustacean larvae over periods of days to weeks we must either find natural tags that are conserved throughout planktonic development or resort to a high frequency characterization of nearshore plankton distribution and circulation patterns (e.g. Natunewicz et al. 2001, Arnold et al. 2005).

The results of our PVD analysis illustrated the effect that differences in vertical distribution can have on expected retention times, but also highlighted the importance of measuring horizontal flows and characterizing their variability at appropriate spatial and temporal scales. Supposing that flows measured at 1 point are representative of a larger area is a critical assump- 
tion that becomes more critical in nearshore environments, where small-scale changes in bathymetry, shoreline orientation, and features such as the 2 submarine canyons flanking our sampling area could play an important role for the retention and/or aggregation of larvae. Thus, future attempts to assess the generality of our observations must involve measurements of horizontal flow variability at a variety of nearshore environments. Finally, hypotheses regarding vertical migration behavior and ontogenetic changes in the range of vertical distribution, as well as swimming responses to transient hydrodynamic features, remain to be tested in the field.

\section{Mortality estimates}

Using vertical life tables to estimate mortality at every transition between larval stages yielded a large number of estimates that were negative, zero, or $>1$ (results not shown). Such values are clearly outside the range of values expected for a closed system, or for a stage distribution that is representative of the larval population. Although it would not be correct to use these values, for instance, to parameterize a population model, it is possible to use them to infer how open the area was in terms of larval dispersal over the duration of our study. On 4 out of $7 \mathrm{~d}$ the mortality estimates for the NII to NIII transition in Balanus glandula were $>1$, suggesting that an input of NII and/or a loss of NIII larvae had occurred. Negative or zero estimates obtained for the transitions from NII to NIII (2 out of 7) and NIII to NIV (5 out of 7 ) in Chthamalus spp. also suggest that there was a loss of NIII, and probably of NII, during the first $2 \mathrm{~d}$. This might be related to ontogenetic differences in swimming abilities and vertical distribution, as NII/NIII larvae are less able to determine their position within the water column (DiBacco, Pineda \& Helfrich unpubl. data), and therefore more prone to entrainment in along-shore flows (see also Yule 1982, Table 7.6, for a summary of sustained swimming performances in cyprids $\left[6 \mathrm{~cm} \mathrm{~s}^{-1}\right]$ vs. nauplii $\left.\left[0.7 \mathrm{~cm} \mathrm{~s}^{-1}\right]\right)$.

Our estimates of larval mortality rates were probably affected by an insufficient spatial and temporal coverage of our sampling. Although the vertical life table method does not require the tracking of individual larval aggregations, instantaneous stage structures utilized in the estimation of mortality are assumed to represent the population's stage distribution (Aksnes \& Ohman 1996). Daily stage distributions observed in this study were highly variable, and suggested that our plankton survey lacked the spatial coverage and replication needed to compensate for small-scale patchiness and advection of early naupliar stages. Fur- thermore, the assumption of constant and equal development time for all larvae in a given stage (Aksnes \& Ohman 1996) could be unrealistic for the larvae of Balanus glandula and Chthamalus spp., which have shown an increase in the variability of stage duration between early and late naupliar stages (Brown \& Roughgarden 1985, Miller et al. 1989). These limitations notwithstanding, our results suggest that the average mortality of barnacle nauplii in nearshore waters fluctuates around 20 to $40 \%$ larvae $\mathrm{d}^{-1}$, which is substantially higher than previously assumed for $B$. glandula and Chthamalus spp. (Gaylord \& Gaines 2000 , p. 774), but within the range of mortality estimates found in the literature for other benthic invertebrate larvae (Rumrill 1990, Morgan 1995, Lamare \& Barker 1999). A nominal mortality rate of 0.05 larvae $\mathrm{d}^{-1}$ has been used repeatedly in modeling studies that describe the distribution and population dynamics of B. glandula and Chthamalus spp. from Northern California and Oregon (see Gaylord \& Gaines 2000, p. 774). This estimate was reportedly obtained from stage-specific counts of Semibalanus balanoides larvae, collected on 3 occasions over a period of $20 \mathrm{~d}$ from a pier in Millport, Scotland (Pyefinch 1949). Despite the caveats mentioned above, we believe that the characteristics of our survey, in terms of target species and sampling design, make the data presented in this contribution more likely to provide a realistic estimate for the nearshore mortality of B. glandula and Chthamalus spp. larvae.

A 4- to 6-fold increase in the mortality rate would have a substantial effect on the number of larvae completing their planktonic development. When constant mortality rates of 20 to $40 \%$ larvae $\mathrm{d}^{-1}$ are used together with a simple exponential decay function to project the numbers of larvae in a closed system after $2.5 \mathrm{wk}$ (average development time for barnacle larvae at $\sim 15^{\circ} \mathrm{C}$ ), the numbers of larvae expected to complete their development are 15 to 450 times smaller than the number expected with a $5 \%$ larvae $\mathrm{d}^{-1}$ mortality. Thus, differences in the mortality rates used to parameterize a model of larval dispersal could affect the predicted travel distances, the relevant larval transport mechanisms, population openness, and ultimately change the expected scales of connectivity among populations (e.g. Lefebvre et al. 2003, Ellien et al. 2004).

Results presented in this paper have implications for the currently dominant view of population openness and connectivity in coastal marine invertebrates. If the potential for limited larval dispersal and high mortality rates inferred from our data are a general feature of similar coastal regions, then populations of sedentary benthic invertebrates with planktonic larvae may be disconnected at small spatial scales, as suggested by recent observational (McQuaid \& Phillips 2000, Porri et 
al. 2006) and modeling studies (Verdier-Bonnet et al. 1997). Future efforts to model the relationship between coastal oceanography and benthic population dynamics must shift from an emphasis on mesoscale processes to a better description of inner-shelf variability and its effect on dispersal and self-recruitment.

Acknowledgements. We are indebted to J. Leichter (Scripps Institution of Oceanography) for his invaluable scientific and logistical support during this study and throughout F.T.'s time at SIO. Field work was greatly facilitated by M. Murray and E. Parnell (SIO). Bathymetric data for La Jolla used in Fig. 1 were provided by S. Elgar (WHOI). Comments by V. Starczak, J. Leichter, J. Jarrett, and 3 anonymous reviewers improved an earlier version of this manuscript. This research was supported by a National Science Foundation grant to J.P. This manuscript is part of F.T.'s doctoral dissertation at the MIT/ WHOI Joint Program in Biological Oceanography.

\section{LITERATURE CITED}

Aksnes DL, Ohman MD (1996) A vertical life table approach to zooplankton mortality estimation. Limnol Oceanogr 41: 1461-1469

Aksnes DL, Miller CB, Ohman MD, Wood SN (1997) Estimation techniques used in studies of copepod population dynamics - a review of underlying assumptions. Sarsia 82:279-296

Alexander SE, Roughgarden J (1996) Larval transport and population dynamics of intertidal barnacles: a coupled benthic/oceanic model. Ecol Monogr 66:259-275

Arnold WS, Hitchcock GL, Frischer ME, Wanninkhof R, Sheng YP (2005) Dispersal of an introduced larval cohort in a coastal lagoon. Limnol Oceanogr 50:587-597

Barnes H, Barnes M (1956) The general biology of Balanus glandula Darwin. Pac Sci 10:415-422

Becker BJ, Fodrie FJ, McMillan PA, Levin LA (2005) Spatial and temporal variation in trace elemental fingerprints of mytilid mussel shells: a precursor to invertebrate larval tracking. Limnol Oceanogr 50:48-61

Bertness MD, Gaines SD, Wahle RA (1996) Wind-driven settlement patterns in the acorn barnacle Semibalanus balanoides. Mar Ecol Prog Ser 137:103-110

Bousfield EL (1955) Ecological control of the occurrence of barnacles in the Miramichi Estuary. Bull Natl Mus Can Biol Ser 137:1-65

Branscomb ES, Vedder K (1982) A description of the naupliar stages of the barnacles Balanus glandula Darwin, Balanus cariosus Pallas, and Balanus crenatus Bruguière (Cirripedia, Thoracica). Crustaceana 42:83-95

Brown SK, Roughgarden J (1985) Growth, morphology, and laboratory culture of larvae of Balanus glandula (Cirripedia: Thoracica). J Crustac Biol 5:574-590

Caley MJ, Carr MH, Hixon MA, Hughes TP, Jones GP, Menge BA (1996) Recruitment and the local dynamics of open marine populations. Annu Rev Ecol Syst 27: $477-500$

Connell JH (1970) A predator-prey system in the marine intertidal region. I. Balanus glandula and several predatory species of Thais. Ecol Monogr 40:49-78

DiBacco C, Levin LA (2000) Development and application of elemental fingerprinting to track the dispersal of marine invertebrate larvae. Limnol Oceanogr 45:871-880

Ellien C, Thiebaut E, Dumas F, Salomon JC, Nival P (2004)
A modelling study of the respective role of hydrodynamic processes and larval mortality on larval dispersal and recruitment of benthic invertebrates: example of Pectinaria koreni (Annelida: Polychaeta) in the Bay of Seine (English Channel). J Plankton Res 26:117-132

Emery WJ, Thomson RE (1998) Data analysis methods in physical oceanography. Pergamon Press, New York

Gaylord B, Gaines SD (2000) Temperature or transport? Range limits in marine species mediated solely by flow. Am Nat 155:769-789

Graham WM, Largier JL (1997) Upwelling shadows as nearshore retention sites: the example of northern Monterey Bay. Cont Shelf Res 17:509-532

Hartley HO (1950) The maximum F-ratio as a short-cut test for heterogeneity of variance. Biometrika 37:308-312

Helfrich KR, Pineda J (2003) Accumulation of particles in propagating fronts. Limnol Oceanogr 48:1509-1520

Hill AE (1998) Diel vertical migration in stratified tidal flows: implications for plankton dispersal. J Mar Res 56: 1069-1096

Hines AH (1979) The comparative reproduction ecology of three species of intertidal barnacles. In: Stancyk SE (ed) Reproductive ecology of marine invertebrates. University of South Carolina Press, Columbia, SC, p 213-234

Johnson KB, Brink LA (1998) Predation on bivalve veligers by polychaete larvae. Biol Bull (Woods Hole) 194:297-303

Lagos NA, Navarrete SA, Veliz F, Masuero A, Castilla JC (2005) Meso-scale spatial variation in settlement and recruitment of intertidal barnacles along the coast of central Chile. Mar Ecol Prog Ser 290:165-178

Lamare MD, Barker MF (1999) In situ estimates of larval development and mortality in the New Zealand sea urchin Evechinus chloroticus (Echinodermata: Echinoidea). Mar Ecol Prog Ser 180:197-211

Lang WH, Forward RB Jr, Miller DC (1979) Behavioral responses of Balanus improvisus nauplii to light intensity and spectrum. Biol Bull (Woods Hole) 157:166-181

Lefebvre A, Ellien C, Davoult D, Thiebaut E, Salomon JC (2003) Pelagic dispersal of the brittle-star Ophiothrix fragilis larvae in a megatidal area (English Channel, France) examined using an advection/diffusion model. Estuar Coast Shelf Sci 57:421-433

Levin LA (1990) A review of methods for labeling and tracking marine invertebrate larvae. Ophelia 32:115-144

Levin LA (2006) Recent progress in understanding larval dispersal: new directions and digressions. Integr Comp Biol 46:282-297

Macho G, Molares J, Vázquez E (2005) Timing of larval release by three barnacles from the NW Iberian Peninsula. Mar Ecol Prog Ser 298:251-260

McQuaid CD, Phillips TE (2000) Limited wind-driven dispersal of intertidal mussel larvae: in situ evidence from the plankton and the spread of the invasive species Mytilus galloprovincialis in South Africa. Mar Ecol Prog Ser 201: 211-220

Miller KM, Blower SM, Hedgecock D, Roughgarden J (1989) Comparison of larval and adult stages of Chthamalus dalli and Chthamalus fissus (Cirripedia: Thoracica). J Crustac Biol 9:242-256

Morgan SG (1995) Life and death in the plankton: larval mortality and adaptation. In: McEdward L (ed) Ecology of marine invertebrate larvae. CRC Press, Boca Raton, FL, p 279-321

Narvaez D, Poulin E, Leiva G, Hernandez E, Castilla JC, Navarrete SA (2004) Seasonal and spatial variation of nearshore hydrographic conditions in central Chile. Cont Shelf Res 24:279-292 
Natunewicz CC, Epifanio CE, Garvine RW (2001) Transport of crab larval patches in the coastal ocean. Mar Ecol Prog Ser 222:143-154

Newman WA, Abbott DP (1980) Cirripedia: the barnacles. In: Morris RH, Abbott DP, Haderlie EG (eds) Intertidal invertebrates of California. Stanford University Press, Palo Alto, CA, p 502-535

Norris KS (1963) The function of temperature in the ecology of the percoid fish Girella nigricans (Ayres). Ecol Monogr 33:23-62

Pineda J (1991) Predictable upwelling and the shoreward transport of planktonic larvae by internal tidal bores. Science 253:548-551

Pineda J (1994a) Internal tidal bores in the nearshore: warmwater fronts, seaward gravity currents and the onshore transport of neustonic larvae. J Mar Res 52:427-458

Pineda J (1994b) Spatial and temporal patterns in barnacle settlement rate along a southern California rocky shore. Mar Ecol Prog Ser 107:125-138

Pineda J, López M (2002) Temperature, stratification and barnacle larval settlement in two Californian sites. Cont Shelf Res 22:1183-1198

Porri F, McQuaid CD, Radloff S (2006) Spatio-temporal variability of larval abundance and settlement of Perna perna: differential delivery of mussels. Mar Ecol Prog Ser 315: 141-150

Pyefinch KA (1949) Short-period fluctuations in the numbers of barnacle larvae, with notes on comparisons between pump and net plankton hauls. J Mar Biol Assoc UK 28: 353-369

Rothlisberg PC, Miller CB (1983) Factors affecting the distribution, abundance, and survival of Pandalus jordani (Decapoda, Pandalidae) larvae off the Oregon coast. Fish Bull 81:455-472

Roughgarden J, Gaines SD, Possingham H (1988) Recruitment dynamics in complex life cycles. Science 241: 1460-1466

Rumrill SS (1990) Natural mortality of marine invertebrate larvae. Ophelia 32:163-198

Scheltema RS (1968) Dispersal of larvae by Equatorial ocean currents and its importance to the zoogeography of shoalwater tropical species. Nature 217:1159-1162

Shanks AL (1983) Surface slicks associated with tidally forced internal waves may transport pelagic larvae of benthic invertebrates and fishes shoreward. Mar Ecol Prog Ser 13: 311-315

Shanks AL, Grantham BA, Carr MH (2003) Propagule disper-

Editorial responsibility: Otto Kinne (Editor-in-Chief), Oldendorf/Luhe, Germany sal distance and the size and spacing of marine reserves. Ecol Appl 13:159-169

Swearer SE, Caselle JE, Lea DW, Warner RR (1999) Larval retention and recruitment in an island population of a coral-reef fish. Nature 402:799-802

Tapia FJ, Pineda J, Ocampo-Torres FJ, Fuchs HL, Parnell PE, Montero P, Ramos S (2004) High-frequency observations of wind-forced onshore transport at a coastal site in Baja California. Cont Shelf Res 24:1573-1585

Thomson J, Elgar S, Herbers THC (2005) Reflection and tunneling of ocean waves observed at a submarine canyon. Geophys Res Lett 32:L10602, doi:10610.11029/ 12005GL022834

Underwood AJ (1997) Experiments in ecology: their logical design and interpretation using analysis of variance. Cambridge University Press, New York

Underwood AJ, Fairweather PG (1989) Supply-side ecology and benthic marine ecology. Trends Ecol Evol 4:16-20

Verdier-Bonnet C, Carlotti F, Rey C, Bhaud M (1997) A model of larval dispersion coupling wind-driven currents and vertical larval behaviour: application to the recruitment of the annelid Owenia fusiformis in Banyuls Bay, France. Mar Ecol Prog Ser 160:217-231

Wares JP (2001) Patterns of speciation inferred from mitochondrial DNA in North American Chthamalus (Cirripedia: Blanomorpha: Chthamaloidea). Mol Phylogenet Evol 18:104-116

Warner RR, Cowen RK (2002) Local retention of production in marine populations: evidence, mechanisms, and consequences. Bull Mar Sci 70:245-249

Winant CD (1983) Longshore coherence of currents on the Southern California shelf during the summer. J Phys Oceanogr 13:54-64

Winant CD, Bratkovich AW (1981) Temperature and currents on the Southern California shelf: a description of the variability. J Phys Oceanogr 11:71-86

Wing SR, Botsford LW, Largier JL, Morgan LE (1995) Spatial structure of relaxation events and crab settlement in the northern California upwelling system. Mar Ecol Prog Ser 128:199-211

Yule AB (1982) The application of new techniques to the study of planktonic organisms. PhD thesis, Marine Sciences Laboratory, University of Wales, Bangor

Zacherl DC, Manriquez PH, Paradis G, Day RW, Castilla JC, Warner RR, Lea DW, Gaines SD (2003) Trace elemental fingerprinting of gastropod statoliths to study larval dispersal trajectories. Mar Ecol Prog Ser 248:297-303

Submitted: September 29, 2006; Accepted: February 2, 2007 Proofs received from author(s): July 14, 2007 